\title{
PENGARUH KOMUNIKASI DAN DISIPLIN KERJA TERHADAP KINERJA KARYAWAN PADA PT. BINTANG BALI INDAH DI DENPASAR
}

\author{
Kadek Udiani ${ }^{1}$ \\ Desak Gde Sayang Adnyani ${ }^{2}$ \\ ${ }^{1,2}$ Fakultas Ekonomi Universitas Ngurah Rai, Bali, Indonesia \\ e-mail : kadekudiani.bali@gmail.com / telp : +6285 63748598
}

\begin{abstract}
ABSTRAKSI
Tujuan dalam penelitian ini adalah untuk mengetahui pengaruh komunikasi dan disiplin kerja secara parsial dan simultan terhadap kinerja karyawan pada PT. Bintang Bali Indah Denpasar. Untuk mencapai tujuan tersebut dilakukan penelitian dengan kuesioner terhadap 81 orang responden, untuk selanjutnya dilakukan analisis dengan menggunakan analisis regresi linier berganda, determinasi, t-test (uji-t) dan F-test. Dari hasil analisis yang sudah dilakukan, didapatkan hasil bahwa komunikasi dan disiplin kerja secara parsial dan secara simultan berpengaruh positif dan signifikan terhadap kinerja karyawan pada PT. Bintang Bali Indah Denpasar. Kinerja karyawan pada PT. Bintang Bali Indah Denpasar dipengaruhi oleh komunikasi dan disiplin kerja sebesar 65,9\% sedangkan sisanya dipengaruhi oleh faktor-faktor lain. Komunikasi merupakan variabel yang berpengaruh dominan terhadap kinerja karyawan PT. Bintang Bali Indah Denpasar, karena mempunyai standarzed cofficients beta yang lebih besar jika dibandingkan dengan variabel disiplin.
\end{abstract}

Kata Kunci : komunikasi, disiplin dan kinerja

\begin{abstract}
The purpose of this study is to determine the effect of communication and work discipline partially and simultaneously on the performance of employees at PT. Bintang Bali Indah Denpasar. In order to achieve the above objectives, a questionnaire of 81 respondents was conducted, to be analyzed by using multiple linear regression analysis, determination, $t$-test (t-test) and $F$-test. From the results of the analysis that has been done, obtained the result that communication and discipline work partially and simultaneously have a positive and significant impact on employee performance at PT. Bintang Bali Indah Denpasar. Employee performance at PT. Bintang Bali Indah Denpasar is influenced by communication and work discipline of $65.9 \%$ while the rest is influenced by other factors. Communication is a variable that has a dominant influence on the performance of employees of PT. Bintang Bali Indah Denpasar, because it has higher beta cofficients beta when compared with variable discipline.
\end{abstract}

Keywords: communication, discipline and performance 


\section{PENDAHULUAN}

Karyawan adalah aset utama perusahaan yang berharga yang harus dijaga dengan baik. Oleh karena itu, perusahaan dan karyawan harus mampu bekerjasama salah satunya dengan komunikasi yang baik untuk mewujudkan kedisiplinan dalam melakukan setiap pekerjaan sehingga dapat meningkatkan kinerja yang tinggi.

Mangkunegara (2011 : 67) menyatakan bahwa kinerja adalah hasil kerja secara kualitas dan kuantitas yang dicapai oleh seorang karyawan dalam melaksanakan tugasnya sesuai dengan tanggung jawab yang diberikan kepadanya. Rivai (2008:212) menyatakan bahwa kinerja merupakan perilaku nyata yang ditampilkan setiap orang sebagai prestasi kerja yang dihasilkan oleh karyawan sesuai dengan perannya dalam perusahaan. Kinerja karyawan merupakan suatu hal yang sangat penting dalam upaya perusahaan untuk mencapai tujuannya.

Banyak faktor yang mempengaruhi kinerja karyawan, salah satu faktor tersebut adalah komunikasi. Widjaja (2010: 8) menyatakan "Komunikasi adalah penyampaian informasi dan pengertian dari seseorang kepada orang lain. Komunikasi akan dapat berhasil baik apabila sekiranya timbul saling pengertian, yaitu jika kedua belah pihak si pengirim dan si penerima informasi dapat memahami. Gorda (2004 : 163) menyatakan bahwa komunikasi merupakan suatu proses penyampaian informasi dari seseorang kepada orang lain dengan harapan timbul kesamaan pengertian dan persepsi dan kemudian untuk diarahkan kepada suatu tindakan tertentu untuk mencapai tujuan yang telah ditetapkan.

PT. Bintang Bali Indah Denpasar adalah sebuah perusahaan Distribusi yang beralamat di Jalan Cargo No. 9A Ubung Denpasar Utara. Perusahaan ini memiliki karyawan sebanyak 81 orang. Waktu kerja dimulai dari jam 8 pagi sampai dengan jam 5 sore dengan waktu istirahat selama 1 jam dari jam 12 sampai dengan jam 1 siang. Adapun masalah masalah yang menyangkut komunikasi, disiplin kerja dan kinerja yang saat ini ada di PT. Bintang Bali Indah yang perlu mendapat perhatian adalah mengenai komunikasi dalam pemecahan masalah antar karyawan, disiplin karyawan dalam kehadiran kerja. Tingkat absensi karyawan pada PT. Bintang Bali Indah Denpasar bulan Januari - Oktober 2016 cenderung berfluktuasi, dimana persentase tingkat absensi karyawan rata-rata sebesar $4,08 \%$. Ini berarti bahwa tingkat absensi karyawan tergolong tinggi karena menurut Utama (2007:93) menyatakan bahwa tingkat absensi yang wajar berada dibawah 3\%, di atas 3 sampai 10\% dianggap tinggi, sehingga dengan demikian sangat perlu mendapat perhatian serius dari pihak manajemen. Karena tingkat absensi yang tinggi merupakan salah satu indikator adanya permasalahan mengenai disiplin kerja karyawan dan hal ini akan berpengaruh pada kinerja karyawan. Adapun Target penjualan pada PT. Bintang Bali Indah Denpasar belum mencapai $100 \%$ sehingga kinerja dari karyawan harus lebih ditingkatkan. Disamping itu, ada juga karyawan yang lebih mementingkan kepentingan pribadinya jika dibandingkan dengan kepentingan perusahaan.

Berdasarkan latar belakang diatas, maka rumusan masalah dalam penelitian ini adalah : 
a. Bagaimana pengaruh komunikasi dan disiplin kerja secara parsial terhadap kinerja karyawan pada PT. Bintang Bali Indah Denpasar?

b. Bagaimana pengaruh komunikasi dan disiplin kerja secara simultan terhadap kinerja karyawan pada PT. Bintang Bali Indah Denpasar?

\section{METODE PENELITIAN}

Penelitian ini berlokasi di PT. Bintang Bali Indah Denpasar yang beralamat di Jalan Cargo No.9A Ubung Denpasar Utara. Obyek penelitian dalam penelitian dalam penelitian ini adalah pengaruh komunikasi dan disiplin terhadap kinerja karyawan pada PT. Bintang Bali Indah Denpasar. Jenis data yang digunakan dalam penelitian ini yaitu Data Kuantitatif adalah data informasi yang berupa angka-angka atau bilangan. Dalam penelitian ini yang termasuk data kuantitatif adalah jumlah karyawan di PT. Bintang Bali Indah Denpasar dan skor hasil penyebaran kuesioner mengenai komunikasi, disiplin kerja dan kinerja karyawan dan Data kualitatif adalah data informasi yang berbentuk kalimat verbal bukan berupa angka-angka atau bilangan. Yang termasuk data kualitatif pada penelitian ini adalah job deskripsi dan aktivitas organisasi. Penelitian ini menggunakan data primer adalah sumber data yang diperoleh langsung dari sumber aslinya (tidak melalui media perantara). Data primer dalam penelitian ini adalah informasi yang dikumpulkan berdasarkan jawaban responden terhadap kuesioner mengenai komunikasi, disiplin dan kinerja dan data sekunder adalah sumber data penelitian yang diperoleh peneliti secara tidak langsung melalui media perantara (diperoleh dan dicatat oleh pihak lain) yang diperoleh dari tempat penelitian dengan pendekatan observasi, seperti jumlah karyawan, tugas pokok dan fungsi bagian-bagian di PT. Bintang Bali Indah Denpasar.

Pada penelitian ini digunakan model regresi yaitu regresi linier berganda untuk mengetahui perubahan kinerja yang dipengaruhi oleh komunikasi dan disiplin kerja. Kemudian digunakan analisis determinasi berganda dimana analisis ini digunakan untuk mengetahui kontribusi dari variabel komunikasi dan disiplin kerja terhadap variabel kinerja karyawan, yang dinyatakan dalam persentase. Penelitian ini diuji dengan uji-t (t-test) dan uji-F (F-test) dalam penelitian ini perhitungannya menggunakan program IBM SPSS Statistics Version 20.

\section{HASIL DAN PEMBAHASAN}

Teknik analisis linier berganda yang digunakan dalam penelitian ini adalah untuk mengetahui perubahan kinerja yang dipengaruhi oleh komunikasi dan disiplin kerja. Berdasarkan hasil perhitungan, diperoleh nilai konstanta a dan koefisien regresi $b_{1}$ dan $b_{2}$, sebagai berikut :

$$
\begin{array}{ll}
a=2,917 & b_{1}=0,382 \\
b_{2}=0,314
\end{array}
$$

Berdasarkan nilai-nilai tersebut di atas, maka diperoleh persamaan regresi berganda sebagai berikut : $\mathrm{Y}=$ $2,917+0,382 X_{1}+0,314 X_{2}$. Berdasarkan persamaan tersebut, maka pengaruh komunikasi dan disiplin kerja terhadap kinerja karyawan pada PT. Bintang Bali Indah Denpasar dapat diartikan sebagai berikut :
a. Nilai konstanta (a) adalah 2,917 
artinya jika komunikasi dan disiplin bernilai 0 atau tidak ditingkatkan maka kinerja karyawan pada PT. Bintang Bali Indah akan bernilai 2,917 yang berarti kinerja karyawan tidak ada perubahan.

b. Nilai koefisien regresi variabel komunikasi $\left(b_{1}\right)$ bernilai 0,382 artinya setiap peningkatan komunikasi oleh karyawan pada PT. Bintang Bali Indah Denpasar sebesar 1 satuan maka akan meningkatkan kinerja karyawan sebesar 0,382 dengan asumsi variabel lainnya bernilai tetap.

c. Nilai koefisien regresi variabel disiplin $\left(b_{2}\right)$ bernilai 0,314 artinya setiap peningkatan disiplin kerja oleh karyawan pada PT. Bintang Bali Indah Denpasar sebesar 1 satuan maka akan meningkatkan kinerja karyawan sebesar 0,314 dengan asumsi variabel lainnya bernilai tetap.

\section{Analisis Determinasi Berganda}

Analisis determinasi digunakan untuk mengetahui besarnya pengaruh antara variabel bebas yaitu komunikasi dan disiplin terhadap kinerja karyawan pada PT. Bintang Bali Indah Denpasar, yang dinyatakan dalam persentase.

Berdasarkan perhitungan diperoleh nilai koefisien determinasi sebesar 0,659, maka :

$$
\begin{aligned}
& D=R^{2} \times 100 \% \\
& =0,659 \times 100 \% \\
& =65,9 \%
\end{aligned}
$$

Berdasarkan hasil perhitungan determinasi diperoleh hasil 65,9\%, artinya komunikasi dan disiplin memberikan sumbangan terhadap kinerja karyawan 65,9\% sedangkan sisanya $34,1 \%$ disumbangkan oleh faktor-faktor lain yang tidak diteliti dalam penelitian ini.

\section{Uji Parsial (t-test)}

Analisis ini digunakan untuk menguji hipotesis yang telah diajukan pada penelitian ini. Selain itu juga agar dapat melihat dampak variabel independen secara parsial mempengaruhi variabel dependen. Untuk menguji pengaruhnya secara parsial, maka digunakan uji t dengan tingkat signifikansi $\alpha 0,05$.

\section{a. Pengaruh Komunikasi terhadap Kinerja Karyawan pada PT. Bintang Bali Indah Denpasar}

Berdasarkan keseluruhan hasil pengujian, ternyata dengan tingkat keyakinan 95\%, kesalahan 5\% dan derajat bebas 78, diperoleh nilai $\mathrm{t}$ hitung $=7,426$ dan nilai $\mathrm{t}$-tabel $=$ 1,991, sehingga kalau dibandingkan maka nilai t-hitung lebih besar dari nilai tabel dan t-hitung berada pada daerah penolakan Ho. Oleh karena itu, Ho ditolak dan Hi diterima. Ini berarti bahwa komunikasi berpengaruh positif dan signifikan terhadap kinerja karyawan pada PT. Bintang Bali Indah Denpasar.

Berdasarkan hasil pengujian tersebut dapat dijelaskan bahwa komunikasi berpengaruh positif dan signifikan terhadap kinerja karyawan pada PT. Bintang Bali Indah Denpasar, sehingga hipotesis yang menyatakan bahwa komunikasi secara parsial berpengaruh positif dan signifikan terhadap kinerja karyawan pada PT. Bintang Bali Indah Denpasar terbukti kebenarannya. Hasil ini selaras dengan penelitian yang dilakukan oleh Juliadi (2015) yang menemukan bahwa komunikasi dan disiplin berpengaruh positif dan signifikan terhadap kinerja 
karyawan pada PT.Bintang Bali Indah Denpasar.

\section{b. Pengaruh Disiplin Terhadap Kinerja Karyawan di PT. Bintang Bali Indah Denpasar}

Berdasarkan keseluruhan hasil pengujian di atas, ternyata dengan tingkat keyakinan 95\%, kesalahan 5\% dan derajat bebas 78, diperoleh nilai thitung $=7,035$ dan nilai t-tabel $=1,991$, sehingga kalau dibandingkan maka nilai t-hitung lebih besar dari nilai $\mathrm{t}$-tabel dan t-hitung berada pada daerah penolakan Ho. Oleh karena itu, Ho ditolak dan Hi diterima. Ini berarti bahwa disiplin berpengaruh positif dan signifikan terhadap kinerja karyawan pada PT. Bintang Bali Indah Denpasar.

Berdasarkan hasil pengujian tersebut dapat dijelaskan bahwa disiplin berpengaruh positif dan signifikan terhadap kinerja karyawan pada PT. Bintang Bali Indah Denpasar, sehingga hipotesis yang menyatakan bahwa disiplin kerja secara parsial berpengaruh positif dan signifikan terhadap kinerja karyawan pada PT. Bintang Bali Indah Denpasar terbukti kebenarannya. Hasil ini selaras dengan penelitian yang dilaksanakan oleh Hendri Azwar (2015) menemukan bahwa terdapat pengaruh yang signifikan antara Disiplin Kerja Terhadap Kinerja Karyawan di Hotel Grand Inna Muara Padang.

\section{Uji Simultan (F-test)}

Digunakan untuk menguji keberartian koefisien korelasi secara serempak atau bersama-sama. Dalam pengujian ini digunakan $F_{\text {tabel }}=$ $\mathrm{F}_{(\alpha ; \mathrm{dfn} / \mathrm{dfd})} \alpha$ atau taraf kesalahan (level of significancy) yang dipakai dalam pengujian ini adalah sebesar $5 \%$ $(\alpha<0,05)$ dengan dfn (degrees of freedom numerator $=$ derajat bebas pembilang) $\mathrm{n}-\mathrm{k}$, dan dfd (degrees of freedom dominator $=$ derajat bebas penyebut) $\mathrm{n}-\mathrm{k}$. Untuk $\mathrm{k}=3$ dan $\mathrm{n}=$ 81, maka dfn $=3-1=2$, dan dfd $=81$ $3=78$ maka besarnya $\mathrm{F}_{\text {tabel }}={ }_{(\alpha ; \mathrm{dfn} / \mathrm{dfd})}$ yang dicari adalah $\mathrm{F}(5 \%, 2 / 78)$, sehingga besarnya $\mathrm{F}$-tabel adalah 3,114 .

Berdasarkan keseluruhan hasil pengujian, ternyata dengan tingkat keyakinan 95\%, kesalahn 5\% dengan derajat bebas pembilang 2 dan derajat bebas penyebut 78, diperoleh nilai Fhitung sebesar 75,391 dan nilai F-tabel sebesar 3,114, sehingga jika dibandingkan maka nilai F-hitung lebih besar dari nilai F-tabel dan F-hitung berada pada daerah penolakan Ho. Oleh karena itu,Ho ditolak dan $\mathrm{Hi}$ diterima. Ini berarti komunikasi dan disiplin terhadap kinerja karyawan pada PT. Bintang Bali Indah Denpasar berpengaruh positif dan signifikan.

Berdasarkan hasil pengujian tersebut, maka dapat dijelaskan bahwa komunikasi dan disiplin berpengaruh positif dan signifikan terhadap kinerja karyawan pada PT. Bintang Bali Indah Denpasar sehingga hipotesis yang menyatakan bahwa komunikasi dan disiplin kerja secara simultan berpengaruh positif dan signifikan terhadap kinerja karyawan pada PT. Bintang Bali Indah Denpasar terbukti kebenarannya.

Berdasarkan hasil pengujian diperoleh standarzed cofficients beta dari komunikasi $\left(\mathrm{X}_{1}\right)$ sebesar 0,516 dan disiplin $\left(\mathrm{X}_{2}\right)$ sebesar 0,489. Dengan demikian komunikasi merupakan variabel yang berpengaruh dominan terhadap kinerja karyawan pada PT. Bintang Bali Indah Denpasar karena mempunyai standarzed cofficients beta 
yang lebih besar jika dibandingkan dengan variabel disiplin

\section{Simpulan}

Berdasarkan pengujian secara serempak diketahui bahwa variabel komunikasi dan variabel disiplin berpengaruh positif dan signifikan terhadap kinerja karyawan pada PT. Bintang Bali Indah Denpasar. Komunikasi dan disiplin secara simultan berpengaruh positif dan signifikan terhadap kinerja karyawan pada PT. Bintang Bali Indah Denpasar, dimana diperoleh koefisien korelasi sebesar 0,659 yang berarti berkorelasi kuat dan dengan determinasi simultan dimana diperoleh hasil $65,9 \%$ artinya komunikasi dan disiplin memberikan sumbangan terhadap kinerja karyawan sebesar $65,9 \%$ sedangkan sisanya $34,1 \%$ disumbangkan oleh faktor-faktor lain yang tidak diteliti dalam penelitian ini dan hal ini diuji dengan analisis F-test (uji F) dimana diperoleh nilai F-hitung sebesar 75,391, dimana nilai F-hitung tersebut lebih besar dari nilai F-tabel 3,114 sehingga dapat dikatakan bahwa pengaruh secara simultan komunikasi dan disiplin terhadap kinerja karyawan pada PT. Bintang Bali Indah Denpasar adalah positif dan signifikan. Komunikasi merupakan variabel yang berpengaruh dominan terhadap kinerja karyawan pada PT. Bintang Bali Indah Denpasar, karena mempunyai standarzed cofficients beta yang lebih besar jika dibandingkan dengan variabel disiplin.

\section{Saran}

Mengingat secara simultan komunikasi dan disiplin berpengaruh positif dan signifikan terhadap kinerja karyawan, maka sebaiknya pihak PT. Bintang Bali
Indah Denpasar meningkatkan komunikasi dan disiplin kerja karyawan dengan lebih memperhatikan media yang digunakan dalam menyampaikan suatu informasi atau berita dan lebih memperhatikan absensi dari karywan dan ala an-alasan yang kurang tepat dari ketidakhadiran karyawan

\section{REFERENSI}

Dharma Agus, 2009, Gaya Kepemimpinan Yang Efektif Bagi Manajer, Sinar Baru, Bandung

Ega Anggraini, 2014, Pengaruh Komunikasi Organisasi dan Disiplin Kerja Karyawan Terhadap Kinerja Karyawan, Yogyakarta : Universitas Negeri Yogyakarta

Eka Juliadi, 2015, Pengaruh Komunikasi dan Disiplin Kerja Terhadap Kinerja Karyawan Pada Kantor Bersama Samsat Kabupaten Klungkung, Denpasar: Universitas Ngurah Rai

Gorda, IGN, 2004, Pengertian Dasar Manajemen Sumber Daya Manusia, Penerbit Widya Kriya Gematama, Denpasar

Hasibuan SP. Malayu, 2009, Manajemen Sumber Daya Manusia, Edisi Revisi, Bumi Aksara, JakartaD

Hendri Azwar, 2015, Pengaruh Disiplin Kerja Terhadap Kinerja Karyawan Di Hotel Grand Inna Muara Padang, Universitas Negeri Padang

Henry Simamora, 2006, Manajemen Sumber Daya Manusia, Edisi 3, Cetakan 1, Bagian Penerbitan STIE YKPN, Yogyakarta

http://kenkendea.blogspot.com/p/makal ah-badan-usaha.html 
http://perusahaan.web.id/definisi/badanusaha.html

Husein, Umar. 2000. Metodelogi Penelitian, Aplikasi Dalam Pemasaran. Jakarta. PT. Gramedia Pustaka Utama

Mangkunegara Anwar Prabu, 2002. Manajemen Sumber Daya Manusia Perusahaan. Bandung. PT Remaja Rosda Karya

--------, 2009. Evaluasi Kinerja SDM, Penerbit Refika Aditama, Bandung

---------, 2011. Manajemen Sumber Daya Manusia Perusahaan, Remaja Rosdakarya, Bandung

Mathis.L.Robert dan Jackson.H.John. 2001, Manajemen Sumber Daya Manusia, Jakarta : Buku kedua

Moenir, AS., 2010., Kepemimpinan Kerja Peranan Teknik dan Keberhasilannya., Penerbit Bina Aksara, Jakarta

Prawirosentono, Suryadi. 1999. Kebijakan Karyawan. Yogyakarta: BPFE

R. Soekardono, 2002, Ibid, Abdulkadir Muhammad, Hukum Perusahaan Indonesia,Citra Aditya Bakti, Bandung

Rangkuti Freddy, 2008, Bisnis Plan, Cetak Ulang Ke-10, Gramedia Pustaka Utama, Jakarta

Riduwan dan Sunarto, 2011, Pengantar Statistika Untuk Penelitian : Pendidikan, Sosial, Komunikasi, Ekonomi dan Bisnis, Alfabeta, Bandung

Rivai Veithzal, 2008, Manajemen Sumber Daya Manusia Untuk Perusahaan : dari Teori dan
Praktik, PT. RajaGrafindo Persada, Jakarta

Sondang P. Siagian, 2000, Sistem Informasi Untuk Pengambilan Keputusan, Jakarta, Cetakan Ketiga, Gunung Agung

Sugiyono, 2011, Metode Penelitian Pendidikan, Penerbit $C V$. Alfabeta, Bandung

---------, 2012, Statistika Untuk Penelitian, Cetakan Ke-21, Penerbit CV. Alfabeta, Bandung

Sunyoto Danang dan Burhanudin, 2011, Perilaku Organisasi, Cetakan 1, CAPS, Yogyakarta

Sutrisno, Edy. 2010. Budaya Organisasi. Jakarta : Kencana Prenada Media Group

T. Hani Handoko, 2004, Manajemen Personalia dan Sumber Daya Manusia, Yogyakarta, Penerbit BPFE-UGM

Tohardi Ahmad, 2009, Pemahaman Praktis Manajemen Sumber Daya Manusia,Penerbit Mandar Maju, Bandung

Umar Husein, 2008, Metode Penelitian Untuk Skripsi dan Tesis Bisnis, Edisi Kedua, Raja Grafindo Persada, Jakarta

Undang-Undang Nomor 3 Tahun 1982 tentang Wajib Daftar Perusahaan

Usman Husaini dan Akbar R

Purnomo Setiady, 2006, Pengantar

Statiska, Edisi

Kedua, Bumi Aksara, Jakarta.

Utama Mudiartha, 2007, Manajemen Sumber Daya Manusia, Denpasar: Universitas Udayana

Widjaja, H.A.W, 2010, Komunikasi dan Hubungan Masyarakat, Bumi Aksara, Jakarta 